\title{
Revealing the technological modes range for ultrasonic surface hardening of cast iron
}

\author{
Yulia Semenova ${ }^{1, *}$, Yuri Nikitin ${ }^{1}$, and Andrey Rakhimyanov ${ }^{1}$ \\ ${ }^{1}$ Novosibirsk State Technical University, Faculty of Mechanical Engineering and Technologies, \\ 630073 Prospekt K. Marks 20, Novosibirsk, Russia
}

\begin{abstract}
Prospects of using the ultrasonic surface hardening of different materials as a way of achieving a simultaneous strengthening and finishing effects are presented. It is shown that this method is applicable for nonrigid and brittle parts. Thus, it allows processing gray cast iron. Therefore, the paper is devoted to establishing technologically significant parameters of ultrasonic surface hardening of particular gray cast iron. Research was conducted using mathematical modeling of the process. According to the calculations, the application of the modes revealed makes it possible to achieve the depth of the hardened layer up to $2 \mathrm{~mm}$. Moreover, the parameters of the hardened layer, such as the diameter of a single imprint and the maximum intensity of deformation for specified processing conditions are calculated.
\end{abstract}

\section{Introduction}

One of the urgent problems of modern machine production is the formation of specific properties of the surface which differ from the properties of the basic material. The analysis of methods for modifying the surface layer has shown the prospects of using surface plastic deformation methods in the technological processes of manufacturing machine parts. The ultrasonic surface hardening plays a significant role among other methods of surface hardening. This method can be described as a method of surface layer deforming by instrument vibrating with the ultrasonic frequency. In different works it can also be named as "ultrasonic impact treatment" [1], "nanocrystal surface modification" [2], "ultrasonic surface rolling processing" [3,4], "ultrasonic impact peening" [5] "ultrasonic hardening" [6], ultrasonic deformation [7], diamond-ultrasonical treatment [8] etc. This method is widely used in technology to modify the surface layer due to the simultaneous strengthening and finishing effect. It is shown in $[9,10]$ that ultrasonic surface hardening allows forming a hardened surface layer with increased mechanical characteristics: microhardness and stress-strain state. In addition, the imprints of the deforming element create a regular microrelief on the surface. All this combined allows increasing the wear resistance and durability of machine parts. As shown in $[2,9]$, due to the low static force, the ultrasonic surface hardening can also be used for non-rigid, thin-walled parts, as well as parts made of brittle materials. However, it should be noted that the brittle materials have

\footnotetext{
*Corresponding author: yu.semenova@corp.nstu.ru
} 
low ductility. Therefore they are difficult to plastic deformation. That is why it requires a certain approach to the choice of the technological mode. Under the technological mode we understand a set of the following processing parameters: the amplitude and frequency of ultrasonic vibration of the instrument, the frequency of vibrating, the static force of pressing the tool against the surface being machined, the diameter of the deforming element, and the kinematic parameters (feed and speed) that ensure the tool movement over the surface.

This work is aimed at revealing the region of the regime parameters of ultrasonic surface hardening of gray cast iron. In order to reveal the regularities in formatting the characteristics of the surface layer in the process of ultrasonic hardening, theoretical studies were carried out. During studies the interrelationships of the regime parameters with changes in the microgeometry of the processed surface as well as the mechanical properties of the surface layer were revealed. The investigations were based on the known model of ultrasonic plastic deformation described in [11-12].

\section{Theoretical framework}

To describe the motion of the deformer the equation of free oscillations of the rod (1) in the model of ultrasonic plastic deformation the, was used [11]:

$$
\frac{\partial A(t)}{\partial t}=V_{K 0}(x, t)+\frac{\partial A_{0}(x, t)}{\partial t}+\frac{F_{D}(t)}{\rho \cdot c \cdot S}
$$

where $\mathrm{A}(\mathrm{t})=\mathrm{A}(0, \mathrm{t})$ - displacement of the deformer, $\mathrm{V}_{\mathrm{K} 0}=\partial \mathrm{A}\left(\mathrm{x}, \mathrm{t}_{0}\right) / \partial \mathrm{t}, \mathrm{A}_{0}(\mathrm{x}, \mathrm{t})=\mathrm{A}\left(\mathrm{x}, \mathrm{t}_{0}\right)-$ distribution of the vibration velocity and displacements along the length of the waveguide at the time $t_{0}$ (before impact), $F_{D}(t)$ - acting force, $\rho$ - density of the waveguide material, $c-$ spreading speed of longitudinal sound waves in the waveguide, S- square of the waveguide cross section.

It is necessary for ultrasonic surface hardening, to provide a combination of finishing and hardening effects with minimal time and energy costs when the required parameters are achieved. A generalizing characteristic of the hardening and finishing effect can be considered by the diameter of a single imprint $\left(\mathrm{d}_{\mathrm{otp}}\right)$ made by the impact of an ultrasonic instrument. In [11-12], a relation between the value $\left(\mathrm{d}_{\text {otp }}\right)$ and the processing parameters is established:

$$
d_{o t p}=\int 2 \sqrt{D_{c} \cdot h(t)} d t
$$

where $D_{c}$ - diameter of the deforming element, $h(t)$ - depth of tool indentation at time point t.

The depth of the tool indentation $\mathrm{h}(\mathrm{t})$ changes during the deformation in two different dependencies corresponding to the indentation period of the tool (3) during the time t0 - t1 and the reverse phase (4) in the time period $\mathrm{t} 1-\mathrm{t} 2$.

$$
\begin{aligned}
& h_{1}(t)=A_{\max }\left[\sin \left(\omega t+\varphi_{1}\right)-e^{-q \omega t} \sin \varphi_{1}\right], \\
& h_{2}(t)=A_{\max }\left\{\left[\sin \left(\omega t+\varphi_{2}\right)-\left(\sin \omega t_{1}+\varphi_{2}\right) e^{-\frac{q \omega\left(t-t_{1}\right)}{R}}\right]+R h_{\max }\right\},
\end{aligned}
$$


where $A_{\max }$ - amplitude of ultrasonic vibrations, $\omega$ - circular oscillation frequency, $\varphi_{1}=\varphi_{0}$ $+\operatorname{arctg} \mathrm{q}, \varphi_{0}-$ the tool trajectory angle corresponding to the time of starting deformation $\left(t_{0}\right), q=\pi H B \cdot D_{c} / \omega \rho c S, \rho-$ density of the waveguide material, HB - hardness of the material, Dc - diameter of the deforming element, $\mathrm{c}$ - spreading speed of longitudinal sound waves in the waveguide, $S-$ square of the waveguide cross section, $\varphi_{2}=$ $\varphi_{1}+\operatorname{arctg}(\mathrm{q} / \mathrm{R}), \quad R=\left(\frac{D_{c} \cdot 10^{-3}}{2 h_{\max }}\right)^{1 / 3}\left[\frac{3 \pi\left(1-\mu^{2}\right) H D}{E}\right]^{2 / 3}$ - coefficient of elastic recovery, here $\mu-$ Poisson's ratio, E - Young's modulus of the processed material; $\mathrm{h}_{\max }-$ maximum penetration depth of the deformer; HD - dynamic hardness of the processed material, $\mathrm{HD}=\mathrm{HB} \cdot \mathrm{k}(\mathrm{k}=1,5 \div 2,25[13])$.

The time $t_{0}$ is determined by the equation characterizing the change in the deformation indentation depth in the period $t_{0}-t_{1}$ when the left part of equation (2) reaches zero after determining the value of $\phi_{1}$. The value of $\phi_{1}$ is determined by solving the equation (5) taking into consideration the known static force.

The time moments $t_{1}$ and $t_{2}$ are determined by solving of the equations (6) and (7), respectively [11].

Integrating the equation (2) with equations (3) and (4), which describe the change in the indentation depth of the deformer at different stages of deformation, an expression for determining the diameter of the plastic imprint $\left(\mathrm{d}_{\text {otp }}\right)$ can be obtained as (8).

$$
\begin{aligned}
& F_{\text {ст }}=\frac{\pi \cdot H D \cdot D_{c} \cdot A_{\max }}{T}\left(\begin{array}{l}
K_{c}\left\{\frac{\sin \varphi_{1}}{q \omega}\left(e^{-q \omega t_{1}}-1\right)-\frac{1}{\omega}\left[\cos \left(\omega t_{1}+\varphi\right)-\cos \varphi_{1}\right]\right\}+ \\
+\frac{K_{c}}{R}\left\{\frac{\sin \left(\omega t_{1}+\varphi_{2}\right) R \cdot e^{\frac{q \omega t_{1}}{R}}}{q \omega}\right\}\left[e^{-\frac{q \omega t_{2}}{R}}-e^{-\frac{q \omega t_{1}}{R}}\right]- \\
\frac{1}{\omega}\left[\cos \left(\omega t_{2}+\varphi_{2}\right)-\cos \left(\omega t_{1}+\varphi_{2}\right)\right]+\frac{R \cdot h_{\max }}{A_{\max }}\left(t_{2}-t_{1}\right)
\end{array}\right) \\
& \cos \left(\omega \mathrm{t}_{1}+\omega_{1}\right)+\mathrm{qe}^{-\mathrm{q} \omega \mathrm{t}}{ }_{1} \cdot \sin \varphi_{1}=0 \\
& A_{\max }\left[\sin \left(\omega t_{2}+\varphi_{2}\right)-\sin \left(\omega t_{1}+\varphi_{2}\right) \cdot e^{-\frac{q \omega\left(t_{2}-t_{1}\right)}{R}}\right]+R h_{\max }=0, \\
& d_{\text {otp }}=\left.\left.2\left[D c \cdot A_{\max } \cdot\left(\begin{array}{l}
\sin (\omega t) \cdot \cos (\varphi) \cdot e^{q \omega t}+ \\
+\cos (\omega t) \cdot \sin (\varphi) \cdot e^{q \omega t}- \\
-\sin (\varphi)
\end{array}\right) \cdot e^{-q \omega t}\right]\right|_{t 0} ^{\frac{1}{2}}\right|^{t 1}
\end{aligned}
$$

\section{Discussion}

Modelling showed that the value of the diameter of the imprint could be obtained by a various combination of the technological parameters. Fig. 1 shows that each combination of fixed values of the indenter diameter D) and the amplitude (Amax) corresponds to a single value of the static force Fst, which is the maximum under the given processing conditions. 
When moving along the line $\mathrm{d}=$ const, it is possible to obtain a combination of mode parameters that ensure the same diameters of single imprints. It should be noted that each point belonging to this family of lines corresponds to the maximum achievable print size for a particular combination of fixed values (D), (Amax), (Fst).

The diameter of the imprint $\left(\mathrm{d}_{\text {imp }}\right)$ does not exceed $0.2 \mathrm{~mm}$ when $\mathrm{D}=1$. Considering the dimensions of the machined surfaces of gray cast iron parts, further reduction of the imprint diameter is not advisable. Otherwise the processing time of the entire surface is increased by decreasing the feed and speed. In this case, the condition $\mathrm{D} \leq 1 \mathrm{~mm}$ can be one of the limitations for the processing mode parameters. When the indenter diameter (D) equals 20 $\mathrm{mm}$, the value of the ultimate static force reaches $1107 \mathrm{~N}$, which ensures the strain intensity in the surface layer not more than $\varepsilon_{\mathrm{i}, 0}=0.02$. Further increase in $\mathrm{D}$ is not advisable, since a less deformation effect does not provide the required strengthening effect. Thus, the second restriction of the mode parameters is the condition: $\mathrm{D} \geq 20 \mathrm{~mm}$.

Since the inclusions of graphite in gray cast iron can reach sizes up to $0.15 \mathrm{~mm}$, one more restriction can be revealed for the parameters of the ultrasonic surface hardening: the diameter of the imprint $\mathrm{d}=0.2 \mathrm{~mm}$. It should be noted that the different deformation intensity values $(\varepsilon i, 0)$ can be achieved. Fig. 2 shows the combinations of ultrasonic surface hardening parameters, which ensure identical values of the plastic deformation intensity ( $\varepsilon i$, 0 ) at the center of the imprint. Since for each material there is a limiting value of the intensity of deformation, the excess of which can lead to desreasing the hardeness of the material, one more restriction must be established. For gray iron $\varepsilon \mathrm{i}, 0=0.2$ will be the restriction, that limits the value of the intensity of plastic deformation, which determines the maximum possible strengthening effect. The minimum strengthening effect, as shown above, is determined by the restriction $\varepsilon i, 0=0.02$.

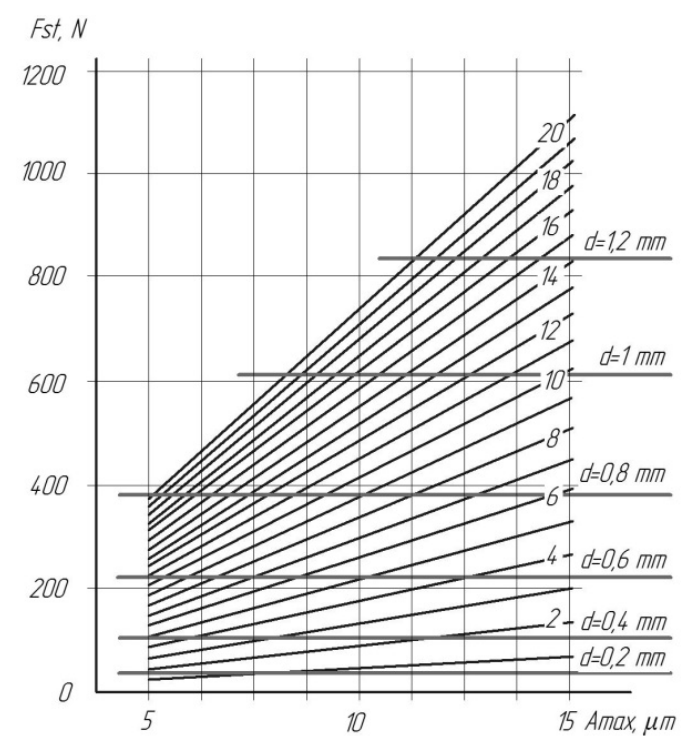

Fig. 1. Distribution of lines of equal imprint diameters $\left(\mathrm{d}_{\mathrm{imp}}\right)$ for different diameters of the deformer (D). 
The calculated zone of the mode parameters for frequency $\mathrm{f}=18 \mathrm{kHz}$ is shown in Fig. 3. In accordance with the constraints described above, this zone is limited by curves 1 and 2 corresponding to the largest and smallest deformer diameters. Curves 3 and 4 determine the minimum and maximum values of the oscillation amplitude. The minimum and maximum strain rates are determined by curves 5 and 6 . Finally, curve 7 determines the minimum allowable diameter of the print.

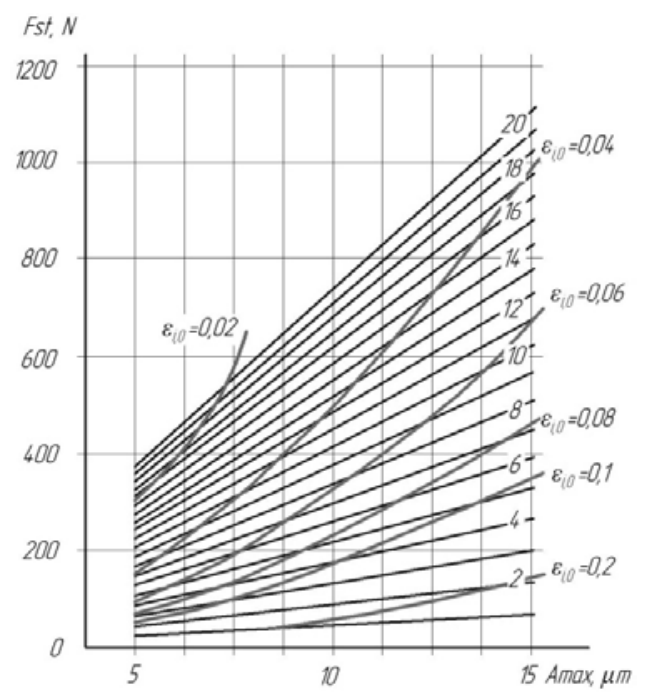

Fig. 2. Distribution of lines of equal strain intensities $(\varepsilon \mathrm{i}, 0)$.

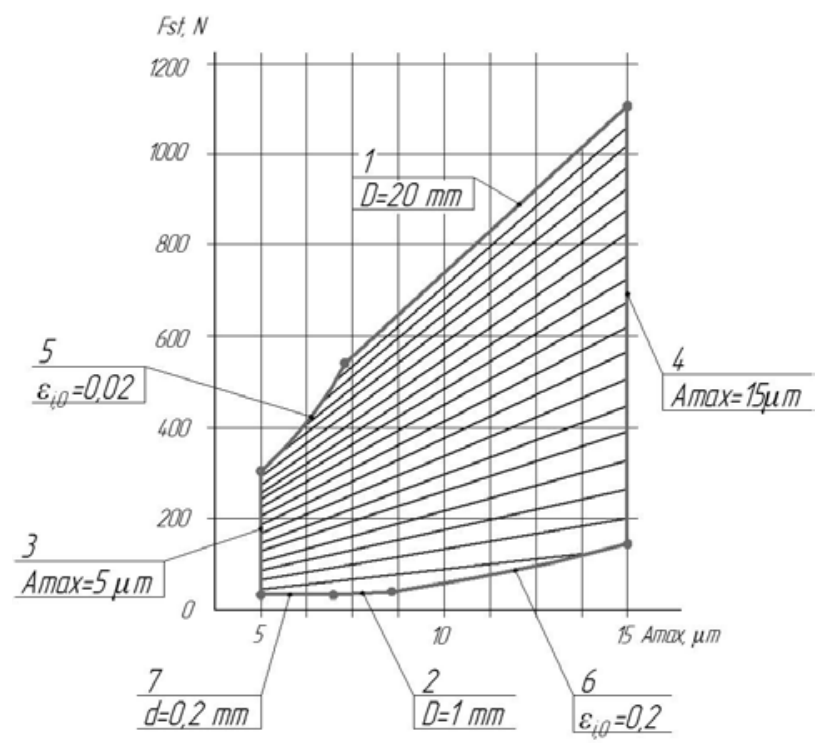

Fig. 3. Calculated range of the mode parameters for ultrasonic surface hardening of cast iron. 


\section{Conclusions}

Realization of processing at the established zone of technological mode allows forming the deformed layer with a depth of up to $2 \mathrm{~mm}$, and reaching the maximum intensity of deformation up to 0.2 , with obtaining imprint diameters up to $1.3 \mathrm{~mm}$

As the frequency increases, the calculated zone shifts upward, to higher values of the static force. At the maximum displacement $(\mathrm{f}=66 \mathrm{kHz}, \mathrm{D}=20 \mathrm{~mm}, \mathrm{Amax}=15 \mu \mathrm{m})$, the static force reaches a value of $1500 \mathrm{~N}$.

Mathematical modeling of the deformation process allowed establishing a calculated range of technologically grounded processing parameters providing the necessary deformation effect in the processing of gray cast iron.

\section{References}

1. V.P. Povarov, O.V. Urazov, M.B. Bakirov, S.S. Pakhomov, I.A. Belunik, Restoration of metal properties of circulation pump blades by the method of surface ultrasonic impact treatment, Thermal Engineering, Vol. 64, Iss. 10 pp. $762-769$ (2017)

2. C. Ma, H. Qin, Z. Ren, S.C. O'Keeffe, J. Stevick, , G.L. Doll, Y. Dong, B. Winiarski, C. Ye, Increasing fracture strength in bulk metallic glasses using ultrasonic nanocrystal surface modification, Journal of Alloys and CompoundsT. Wang, D.-P. Wang, Y. Shen, B.-M. Gong, C.-Y. Deng, Effect of ultrasonic surface rolling processing parameters on $40 \mathrm{Cr}$ surface roughness, Journal of Tianjin University Science and Technology. Vol. 42, Iss. 2, pp. 168-172 (2009)

4. Ch. Minglong, Zh. Deyuan, Ch. Huawei, Q. Wei, L. Jinsheng, Surface nanocrystallization and its effect on fatigue performance of high-strength materials treated by ultrasonic rolling process, Int J Adv Manuf Technol. Vol. 83 pp. 123-131, DOI 10.1007/s00170-015-7485-4 (2016)

5. Q. Yang, D. Wang, S. Wu, S. Li, Research on the effect of ultrasonic impact peening on the fatigue property of 7075-T651 aluminum alloy, Advanced Materials Research: Proceedings of the International Conference on Advanced Engineering Materials and Technology, AEMT 2011; Sanya; China; Vol. 295-297 pp. 1896-1900 (2011)

6. A. Rusinko, Analytical description of ultrasonic hardening and softening, Ultrasonics . Vol. 51, Iss. 6, pp. 709-714 (2011)

7. Kh.M.Rakhimyanov, G.A. Iskhakova, L.L. Karmanov, G.Kh.Grodnikas, The influence of ultrasonic deformation on the steels surface lay formation by sparking alloying with cemented carbide electrode, Elektronnaya Obrabotka Materialov Iss/ 2, P. 17-20 (1993)

8. G.A. Iskhakova, V.P. Gileta, Kh.M. Rakhimyanov, Strucrute and mechanical properties of WC-Co alloy surface layer after diamond-ultrasonical treatment Sverkhtverdye Materialy Iss.5. pp. 54-61 (1991)

9. K. M. Rakhimyanov, Y.V. Nikitin, J. S. Semenova, Surface preparation of machine parts and instruments by ultrasonic impact treatment before coating, Proceedings of The Third International Forum on Strategic Technologies (IFOST-2008) pp. 108-113 (2008)

10. S.V. Veselov, D.E. Golovin, I.A. Bataev, V.G. Burov, Formirovanie napryazhennogo sostoyaniya poverkhnostnykh sloev splavov $v$ rezul'tate impul'snoy ul'trazvukovoy 
obrabotki [Formation of stress state of surface layers of alloys as a result of pulsed ultrasonic treatment]. Obrabotka metallov(tekhnologiya. oborudovanie. instrumenty [Obrabotka metallov: metal working and material science]. Iss. 4 (37). - pp.30-32. (2007)

11. K.M. Rakhimyanov, K.K. Rakhimyanov, Estimating the Parameters of Deformation Action by Ultrasonic Surface Hardening of Metals, IOP Conference Series: Materials Science and Engineering. Vol. 253, iss. 1, 131653 (2017)

12. Kh. M. Rakhimyanov, Yu.V. Nikitin, Y. S. Semenova, The condition of waviness forming at ultrasonic impact treatment of metals, Obrabotka metallov (tekhnologiya, oborudovanie, instrumenty) [Obrabotka metallov: metal working and material science]. Iss. 1(54), pp. 4-9. (2012) (in Russian)

13. Drozd M.S. Opredelenie mehanicheskih svoistv metalla bez razrushenij [Nondestructive determination of the mechanical properties of metal]. Moscow, Metallurgija Publ., 171 p. (1965) 